\title{
MÉTODO IMUNOCITOQUÍMICO PARA A IDENTIFICAÇĂO DE AMASTIGOTAS DO TRYPANOSOMA CRUZI EM CORTES HISTOLOGICOS DE ROTINA (")
}

\author{
Alfredo José Afonso BaRBosa (1)
}

\section{R E S U M O}

A técnica da peroxiđase antiperoxidase foi aplicada para a identificação de amastigotas do T. cruzi em cortes histológicos de rotina. Os tecidos foram obtidos de pacientes chagásicos crônicos e de animais na fase aguda da infecção chagásica. Anti-soros específicos produzidos em coelho contra as cepas $\mathrm{CL}, \mathrm{Y}$ e Ernane do T. cruzi foram utilizados como reagentes primários na técnica imunocitoquímica. Soro de coelho normal foi utilizado como controle negativo e culturas de macrofagos peritoniais de camundongos infectados com tripomastigotas e apresentando abundantes' amastigotas intracelulares foram utilizadas como controles positivos. Coloração positiva ocorreu especificamente nos amastigotas intra e extracelulares em todos os tecidos testados com os anti-soros contra as três diferentes cepas do $\mathbf{T}$. cruzi. Os amastigotas isolados ou formando ninhos intracelulares tornaram-se facilmente identificáveis nas preparações histológicas utilizando-se o pequeno ou médio aumento do microscópio. O presente método aumenta a probabilidade do diagnóstico do parasitismo na doença de Chagas, e evita confundirse amastigotas com oùtros microrganismos morfologicamente semelhantes.

\section{N T R O D U G $\tilde{A} O$}

A identificação de formas amastigotas do T. cruzi em cortes histológicos utilizando técnicas convencionais de coloração é difícil e frequentemente os resultados positivos dependem de grande número de cortes e exame microscópico exaustivo utilizando-se objetiva de grande aumento. Mesmo nestes casos, a identificação dos amastigotas só é possível quando se encontram ninhos intracelulares típicos porque os parasitas se coram inespecificamente com os corantes básicos à semelhança de outras estru. turas celulares. Nos casos de teeidos provenientes de animais na fase aguda da infecção, a identificação rotineira dos parasitas torna-se relativamente fácil apenas porque são mais frequientes; entretanto, continua difícil o diagnóstico daqueles isolados ou com localização extracelular. Clinicamente a doença de Chagas é mais importante na fase crônica quando as lesões teciduais são mais graves; entretanto, nesta fase, torna-se escasso o número de parasitas ${ }^{4}$. Na chamada fase "indeterminada" da doença pouco se sabe a respeito da evolução das lesões, bem como da quantidade relativa e características do parasitismo. Recentemente, alguns Autores tem mostrado que a presença de parasitas no tecido na fase crônica da doença de Chagas, mesmo em sedes insólitas, pode ser mais frequiente do que o presentemente conhecido 1,3 . Portanto, o estudo da patologia da doença de Chagas carece de método histológico que facilite o reconhecimento de amastigotas no tecido, tanto com finalidade diagnóstica como para tornar mais preciso o estudo quantitativo do parasitismo nos diversos órgãos e tecidos.

(*) Trabalho realizado no Departamento de Anatomia Patologica, Faculdade de Medicina da UFMG. 30.000 Belo Horizonte - Brasil, com auxílio financeiro da FINEP (Proc, n. $43 / 83 / 0119 / 00$ ) e CNPq (Proc. n.॰ 30.1851/76)

(1) Professor Adjunto 
BARBOSA, A. J, A. - Método imunocitoquímico para a identificação de amastigotas do Trypanosoma cruzi em cortes histológicos de rotina. Rev. Inst.. Med. trop. São Paulo 27:293-297, 1985.

Tendo em vista, portanto, reconhecer os parasitas com alto grau de especificidade em tecidos preparados rotineiramente e contornar as dificuldades acima descritas, procedeu-se à execução do presente trabalho.

\section{MATERIAL E METODO}

Obteve-se amostras sangüíneas de coelhos entre 1 e 2 anos após terem sido inoculados, via intra-peritonial, com $10^{7}$ tripomastigotas provenientes de camundongo irradiado (cepas $\mathrm{Y}$ e CL), e, via ocular, com inóculo de 3000 a 4000 tripomastigotas provenientes de $\mathbf{D}$. maximus (cepa Ernane). Escolheu-se para aplicação nas técnicas imunocitoquímicas os anti-soros com maiores titulos de anticorpos líticos contra $\mathbf{T}$. cruzi; em seguida foram diluídos em tampão fosfato salino (PBS), $\mathrm{pH} 7,2$ nas proporções $1: 50,1: 200,1: 400,1: 800$ e $1: 1.600$.

Os tecidos estudados foram provenientes de individuos humanos e de animais de experimentação, os primeiros de chagásicos crônicos e os segundos com doença de Chagas aguda. Os tecidos testados, fixados em formol a $10 \%$ e incluidos em parafina como de rotina, foram os seguintes: placentite chagásica humana, cardite chagásica crônica, parede de bexiga urinária de camundongos inoculados via intraperitonial com tripomastigotas da cepa $\mathrm{Y}$; coração, baço, intestino e músculo esquelético de cães inoculados com as cepas Colombiana e Berenice.

Os cortes histológicos foram hidratados como de rotina, lavados em PBS, aplicando-se em seguida, sobre os mesmos a técnica da imunoperoxidase "PAP" de STERNBERGER?. Na primeira camada aplicou-se os anti-soros dos coelhos chagásicos, infectados com as diferentes cepas e nas várias diluições acima descritas; em seguida, as preparações foram incubadas em câmara úmida a $4^{\circ} \mathrm{C}$ por $18-24$ horas. $\mathrm{Na}$ segunda camada aplicou-se a fração IgG de cabra contra IgG de coelho (Miles-Yeda Ltd, Israel) na diluição 1:80 e, na terceira camada, - complexo peroxidase-antiperoxidase (MilesYeda Ltd, Israel), diluído 1:250. Para revelar - local da reação da peroxidase as preparações foram incubadas em solução de $30 \mathrm{mg} \%$ de te: trahidrocloreto de 3,3-diaminobenzidina (D.A.B.) com $0,03 \%$ de peróxido de hidrogênio. Após a reação com o D.A.B. as preparações foram con. tra-coradas com hematoxilina.

Como controle negativo utilizou-se, em substituição ao anti-soro de coelho chagásico, soro de coelho normal ou apenas PBS. Como controle positivo utilizaram-se preparações de cultura de macrófagos peritoniais de camundongo, posteriormente infectadas com $T$. cruzi, cepa $Y$, e após 48 horas, fixadas em líquido de Bouin e coradas pelo Giemsa lento quando se observaram numerosos macrófagos contendo grande quantidade de amastigotas no interior do citoplasma. Após examinadas, estas preparações foram rehidratadas e deixadas durante 2 horas em álcool a $70 \%$, quando se observou completa descoloração das mesmas. Em seguida foram tratadas pelo método imunocitoquímico acima descrito.

\section{RESULTADOS}

No exame das preparações histológicas incubadas com soro de coelho chagásico nas diluiçōes de 1:400, 1:800 e 1:1600 observou-se a coloração marrom característica do $\mathrm{DAB}$ limi. tada apenas aos amastigotas. Em alguns casos a parede interna do pseudocisto em fibrocélulas musculares corou-se também à semelhança dos parasitas (Fig. 1B). A membrana celular e o cinetoplasto dos parasitas coraram-se fortemente, tornando nítidos os limites entre estes e o tecido e permitindo fácil visualização dos mesmos já no pequeno ou médio aumento do $\mathrm{mi}$. croscópio, quer apresentassem localização in. tra ou extracelular (Figs. 1 e 2). Na placenta, bem como nos tecidos de animais sacrificados na fase aguda da doença, com freqüência amastigotas isolados ou em pequenos grupos po. diam ser detectados no espaço intercelular. Os três diferentes tipos de anti-soros foram posi. tivos em todos os tecidos testados. Entretanto, para as maiores diluiçōes, ou seja 1:800 e 1:1.600 os anti-soros de coelhos infectados com as ce. pas Ernane e Y apresentaram reação positiva mais forte do que o daqueles infectados com a cepa CL. Nas demais diluições tornou-se difi cil encontrar diferenças entre os três tipos de anti-soros utilizados. Os amastigotas das preparaçōes de cultura de macrófago utilizados como controles positivos coraram-se intensa. mente pelo D.A.B. e as demais células do meio, bem como os núcleos e membrana celular dos 
BARBOSA, A. J. A. - Metodio imunocitoquimico para a identificaçüo de amastigotas do Trypanosoma cruxi em cortes histológieos de rotina, Rev. Inst. Med. trop. São Paulo z7:293-297, 1985.

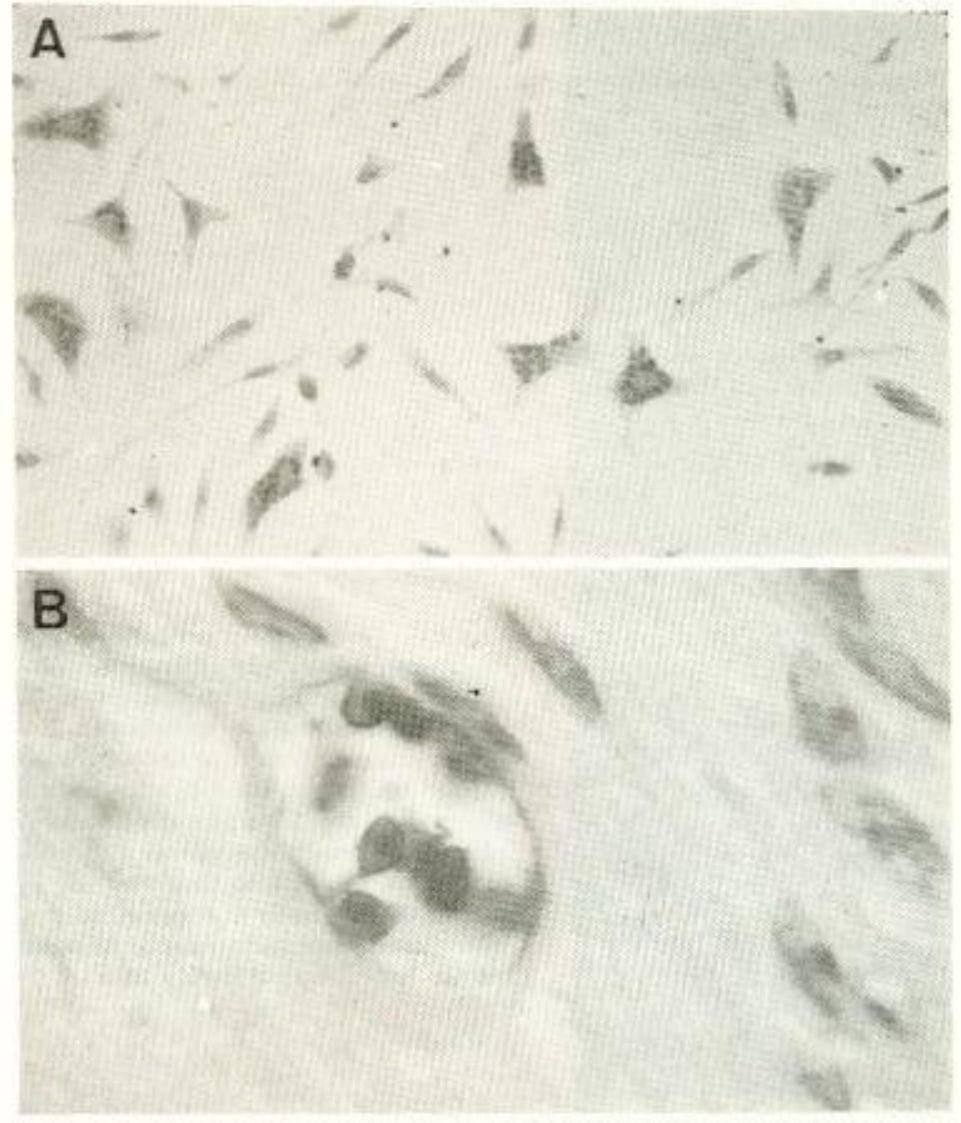

Fig. 1 - Preparaçōes histológicas coradas pelo método da imunoperoxidase (PAP) para evidenciar amastigotas do T. cruzi. Contracoloração: Hematoxilina. A - controle positivo: cultura de macrófagos peritonfais de camundongo contendo no citoplasma numerosos amasti. gotas $(200 x)$; B e C - cortes de tecidos fixados em formol a $10 \%$ e inclui. dos em parafina, mostrando 1 ninho de amastigotas em tecido muscular liso (B) e amastigotas em tecido gorauroso (C) de camundongo inoculado com a cepa $\mathrm{Y}$ do $\mathbf{T}$. cruzi, na tase aguda da doença $(1000 x)$,

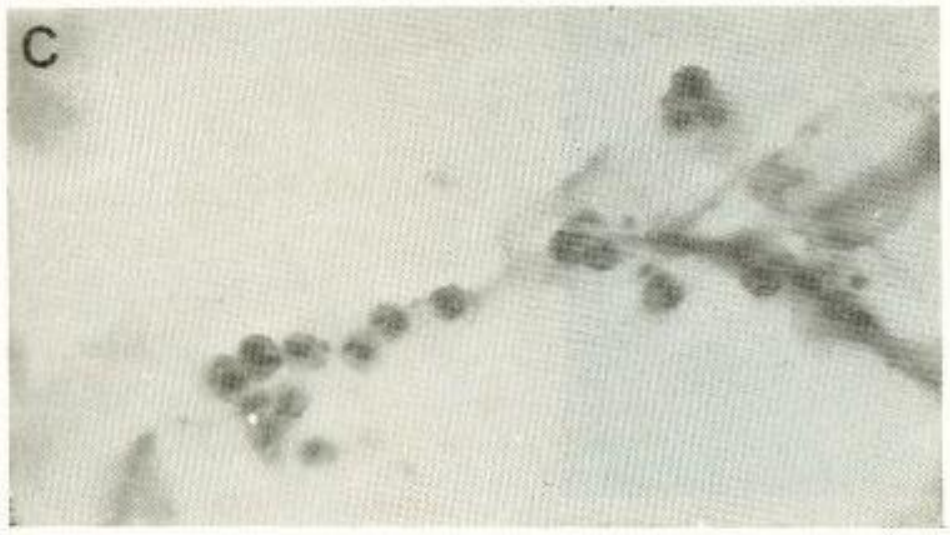

macrófagos parasitados coraram-se apenas pela hematoxilina. (Fig. 1A). Os controles negativos coraram-se apenas pela hematoxilina, não se tendo nenhum indício de coloração pelo D.A.B. nas diluiçōes de 1:400 e maiores.

\section{DISCUSSAO}

$\hat{\mathrm{E}}$ muito conhecido entre os patologistas a inespecificidade da reaçäo inflamatória nos ór- gãos de choque da doença de Chagas crônica. Sendo escasso o número de parasitas, a procura destes para se confirmar o diagnóstico his topatológico, ou para auxiliar no trabalho de se estudar a patogênese da doença, exige gran. de número de cortes histológicos e procura exaustiva ao microscópio ${ }^{3}$. Por outro lado, o encontro de figuras suspeitas, quando nâo for. mam ninhos intracelulares caracteristicos, nem sempre podem ser diagnosticados com preci. 
BARBOsA, A. J. A. - Método imunocitoçufmico para a identificaçio de amastigotas do Trypanosoma cruxi em cortes histológicos de rotina. Rev. Inst. Med. trop. São Paulo 27:293-297, 1985.

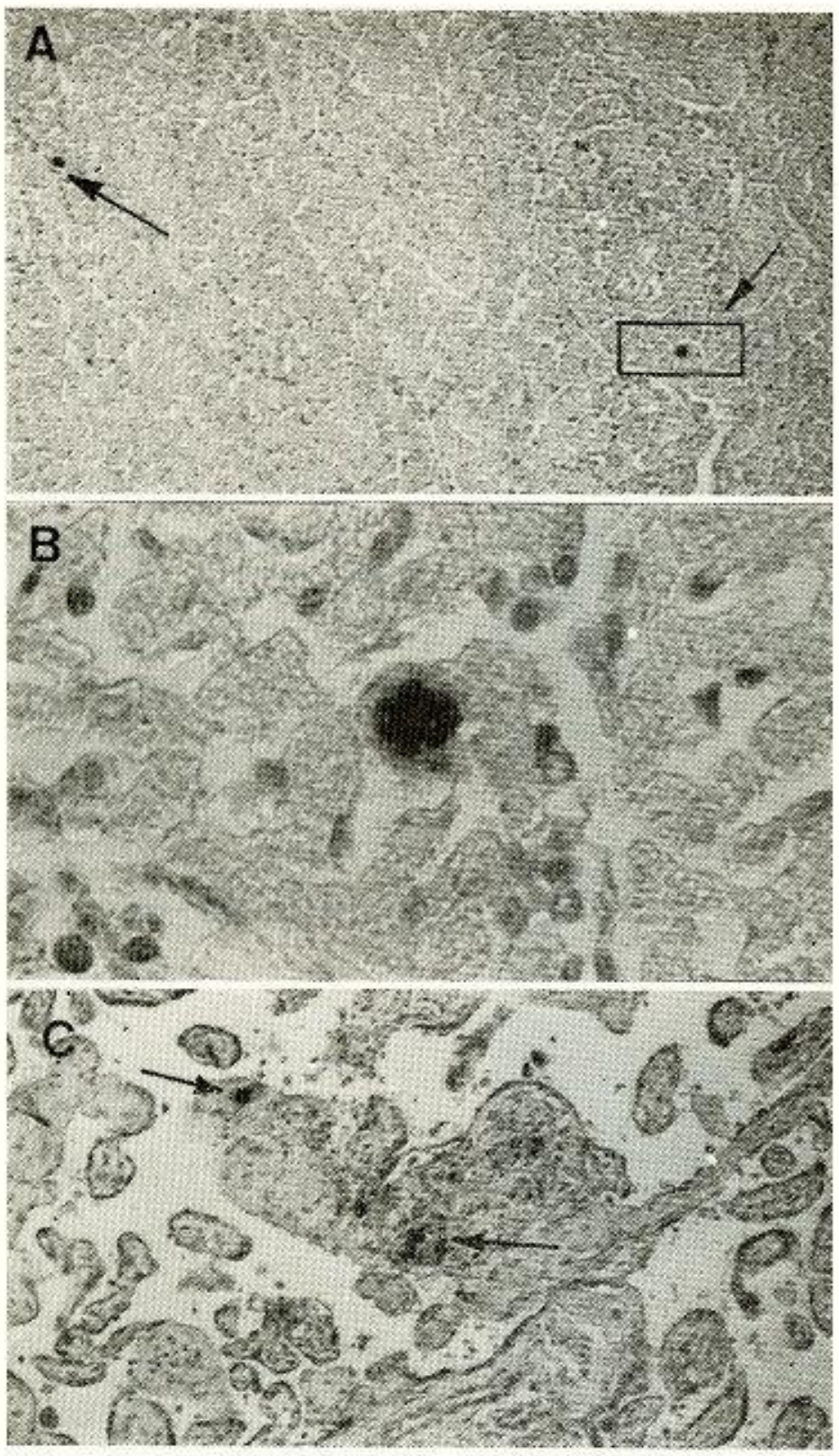

Fig, 2 - Preparaçēes histológicas cora. das pelo método da imunoperoxidade (PAP) para evidenciar amastigotas do $T$. cruxi, Contracoloraçio: Hematoxilina. A - visīo panorâmica de corte transyersal de musculo cardíaco de căo inoculado com a cepa Berenice mostrando 2 ninhos de amastigotas (setas) fortemente corados e bem evidentes $(80 x) ; B-$ detalhe de A (1000x): C - placentite chsgásica humana mostrando ninhos de amas. tigotus (setas) bem evidentes (200x)

são. O parasitismo discreto de células macrofágicas no conjuntivo ou a localizaçāo dos amastigotas no interstício, em pequenos grupos ou isolados, torna-se de difícil avaliação histológica. Além disto, os amastigotas podem adquirir características morfológicas semelhantes a outros microrganismos intracelulares co. mo Toxoplasma e Histoplasma capsulatum, trazendo dificuldades para o diagnóstico diferencial.
Utilizando o método da imunoperoxidase com aplicação de soro de coelho chagásico agora descrito, para evidenciar os amastigotas com alto grau de especificidade e nitido contraste com os tecidos circunvizinhos, tanto formas iso. lacias do parasita como ninhos intracelulares do mesmo podem ser facilmente identificados já no pequeno ou médio aumento do microscópio, reduzindo muito o tempo de pesquisa e prova. velmente o número de låminas a serem estu. dadas. 
BARBOŚ, A. J. A. - Método imunocitoquímico para a identificação de amastigotas do Trypanosoma cruzi em cortes histológicos de rotina. Rev. Inst. Med. trop. Săo Paulo 27:293-297, 1985.

Uma vez que diferentes subespécies do $\mathbf{T}$. cruzi são antigenicamente semelhantes 2,5 . ocorre reação imune cruzada destas com o anti. so. ro primário, não permitindo diferenciação imunocitoquímica entre as várias cepas do parasita, quando se utilizam anticorpos policlonais como no presente trabalho. Neste aspecto os resultados do presente estudo coincidem com o observado na identificação imunocitoquímica das diferentes espécies de Leishmanias ${ }^{5}$. Por outro lado, o presente método vem facilitar e tornar mais acurado o diagnóstico de amastigotas no tecido na doença de Chagas humana e experimental, qualquer que seja a cepa de origem dos mesmos, utilizando-se apenas anti-soro contra uma determinada espécie.

\section{SUMMARY}

\section{Immunocytochemical method of identification of Trypanosoma cruzi amastigotes in routinely prepared histological sections}

The peroxidase-antiperoxidase (PAP) method was applied for identification of amastigotes of Trypanosoma cruzi in routinely prepared histological sections. The tissue specimens were obtained from patients with chronic Chagas' disease and from mice and dog with acute Chagas' disease. Specific rabbit antisera were produced against CL, $\mathrm{X}$ and Ernane strains of T. cruzi and were used as primary reagents. Normal rabbit serum and phosphate buffered saline were used as negative controls and amas. tigotes within macrophages cultured from mice peritonium were used as positive controls.

Positive staining was localized specifically in amastigotes in all the tissues treated with the antisera against the different strains of T. cruzi. The isolated or intracellular nests of amastigotes were easily identified in histologi. cal sections using the small or medium size magnifications of the microscope. The present method increases the probability of microsco: pic diagnosis of parasites in Chagas' disease and helps to prevent confusion of amastigotes with other morphologically similar infective agents.

\section{AGRADEGIMENTOS}

O autor deseja expressar seus agradecimentos aos Profs. Zigman Brenner e Eliane Lages, Instituto de Pesquisas René Rachou, Belo Horizonte; Luiz E. Ramirez, Departamento de Parasitologia, Universidad de Antioquia, Medellin, Colombia; W.L. Tafuri, UFOP, Ouro Preto; Fausto E.L. Pereira, UFES, Vitória; Ana Maria A. Lana, UFMG, Belo Horizonte e Hipólito O. Almeida, FMTTM, Uberaba, pelas facilidades permitidas na obtenção de parte do material utilizado neste trabalho; à Maria de Lourdes P. Orsini e Nízia F.L. de Paula pela assistência técnica.

\section{REFERENCIAS BIBLIOGRAFICAS}

1. ALMEIDA, H. O.; TEIXEIRA, V. P. A. \& OLIVEIRA, A. C. A. - Flebite com parasitísmo em supra-renais de chagásicos crônicos. Arq. Bras. Cardiol. 36: 341-344, 1981.

2. ARAÚJO, F. G.; SHARMO, S. D.; TASI, V.; COX, P. \& REMINGTON, J. S. - Monoclonal antibodies to stages of Trypanosoma cruzi: characterization and use for antigen detection. Infect. \& Immun. 3z: 344-349, 1982.

3. BARBOSA Jr., A. A. \& ANDRADE, Z. A. - Identifica. ção de Trypanosoma cruzi nos tecidos extracardíacos de portadores de miocardite crônica chagásica. Rev. Soc. Bras. Med. Trop. I7: 123-126, 1984.

4. BOGLrolo, L. - Patologia. 3,a edição. Rio de Janeiro, Guanabara Koogan, 1981, capitulo 13, 342-395.

5. FLINT, J. E.; SCHECHTER, M.; CHAPMAN, M. D. \&. MILES, M. A. - Zymodeme and species specificities of monocional antibodies raised against Trypanosoma cruzi. Trans. Royal Soc. Trop. Med. \& Hyg. 78: $193-$ $202,1984$.

6. LIVMI, N.; ABRAMOWITZ, A.; LONDNER, M.; OKON, E. \& MORAG, A. - Immunoperoxidase method of identification of Leishmania in routinely prepared histolo. gical sections. Virchows Arch. Pathol. Anat. 401: 147$151,1983$.

7. STERNBERGER, L. A. - Immunocytochemistry. 2nd edition. New York, A Wiley Medical Publication, 1979, Chapter 5, pgs. 104-169.

Recebido para publicaçāo em 6/11/1984. 